\title{
Clinical prognostic indicators of dysphagia following prolonged orotracheal intubation in ICU patients
}

\author{
Danielle Pedroni Moraes ${ }^{1}$, Fernanda Chiarion Sassi ${ }^{2}$, Laura Davison Mangilli ${ }^{3}$, Bruno Zilberstein ${ }^{4}$ \\ and Claudia Regina Furquim de Andrade $2^{2^{*}}$
}

\begin{abstract}
Introduction: The development of postextubation swallowing dysfunction is well documented in the literature with high prevalence in most studies. However, there are relatively few studies with specific outcomes that focus on the follow-up of these patients until hospital discharge. The purpose of our study was to determine prognostic indicators of dysphagia in ICU patients submitted to prolonged orotracheal intubation (OTI).

Methods: We conducted a retrospective, observational cohort study from 2010 to 2012 of all patients over 18 years of age admitted to a university hospital ICU who were submitted to prolonged OTI and subsequently received a bedside swallow evaluation (BSE) by a speech pathologist. The prognostic factors analyzed included dysphagia severity rate at the initial swallowing assessment and at hospital discharge, age, time to initiate oral feeding, amount of individual treatment, number of orotracheal intubations, intubation time and length of hospital stay.

Results: After we excluded patients with neurologic diseases, tracheostomy, esophageal dysphagia and those who were submitted to surgical procedures involving the head and neck, our study sample size was 148 patients. The logistic regression model was used to examine the relationships between independent variables. In the univariate analyses, we found that statistically significant prognostic indicators of dysphagia included dysphagia severity rate at the initial swallowing assessment, time to initiate oral feeding and amount of individual treatment. In the multivariate analysis, we found that dysphagia severity rate at the initial swallowing assessment remained associated with good treatment outcomes.
\end{abstract}

Conclusions: Studies of prognostic indicators in different populations with dysphagia can contribute to the design of more effective procedures when evaluating, treating, and monitoring individuals with this type of disorder. Additionally, this study stresses the importance of the initial assessment ratings.

\section{Introduction}

The clinical relevance of dysphagia after extubation is profound; it occurs frequently and affects patients across all medical and surgical diagnostic categories [1,2]. For many hospitalized, intubated patients, underlying conditions may interact with dysphagia to produce aspiration, pneumonia, and/or respiratory compromise. Dysphagia

\footnotetext{
* Correspondence: clauan@usp.br

${ }^{2}$ Department of Physiotherapy, Speech-Language and Hearing Sciences, and Occupational Therapy, School of Medicine, University of São Paulo, Rua Ovídeo Pires de Campos, 186, Cerqueira César, CEP 054030-010 São Paulo, SP, Brazil

Full list of author information is available at the end of the article
}

even without aspiration can interfere with nutrition and delay clinical recovery [2].

Prolonged intubation, typically defined as longer than 48 hours [1,3-6], is thought to contribute to swallowing dysfunction. The development of postextubation swallowing dysfunction is well documented in the literature with high prevalence in most studies, ranging from 44 to 87\% [7-11]. However, there are relatively few studies with specific outcomes that focus on the follow-up of these patients until hospital discharge. High-quality studies are relevant to assess the influence of prolonged intubation on dysphagia and to determine which factors put patients at greater risk [11].

\section{Biomed Central}

(c) 2013 Moraes et al.; licensee BioMed Central Ltd. This is an open access article distributed under the terms of the Creative Commons Attribution License (http://creativecommons.org/licenses/by/2.0), which permits unrestricted use, distribution, and reproduction in any medium, provided the original work is properly cited. 
Longer intubation duration has been correlated to dysphagic patients [7,12-14] and has also been reported to be an independent predictor of dysphagia severity $[15,16]$. The higher risk of dysphagia post extubation was reported in those patients with Glasgow Coma Scale scores of $\leq 14$ [8] or age $\geq 55$ yrs $[8,16]$. In contrast, another study found that neither age nor the duration of intubation was correlated with an increase in swallowing dysfunction in post orotracheal intubation (OTI) patients [1]. Post prolonged intubation swallowing disorder extends the time to begin the oral myofunctional/swallowing assessment, to return to normal oral feeding and delays subsequent hospital discharge [14,15,17].

When reviewing the literature, it appears that detailed analyses on the relationship between the degree and outcome of swallowing problems and the type and degree of primary treatment are very limited. A clearer understanding of prognostic indicators has the potential to enable the rehabilitation team to better predict recovery and facilitates appropriate and cost-effective care for individuals with swallowing disorders $[18,19]$. Studies have examined general prognostic indicators of swallowing function in different diseases. These indicators include: age $[20,21]$; severity of the disease [22-24]; cognitive status $[18,25]$; dysphagia severity level at hospital admission and/or discharge [22,26-28]; presence of feeding tube [29]; time to achieve oral feeding status $[14,17,30]$; time to tracheostomy weaning [14,31]; ventilator status $[17,25]$; amount of treatment $[14,18,26]$; and length of hospital stay $[12,32]$.

Carefully selected process indicators should be used when evaluating the quality of the health care provided to patients with dysphagia. To enable a fair evaluation of clinical practice, process indicators should reflect expected practices in local settings, such as those found in relevant clinical guideline recommendations [19,33]. Many of the process indicators used previously for dysphagia management evaluations are not based on sound levels of evidence, which reflects the challenge of research in this field [33]. Therefore, the purpose of our study was to determine prognostic indicators related to dysphagia at hospital discharge of intensive care unit (ICU) patients submitted to prolonged orotracheal intubation.

\section{Materials and methods}

Using the School of Medicine Hospital - University of São Paulo, Brazil - medical records system, we conducted a retrospective, observational cohort study of extubated ICU patients who had undergone a bedside swallow evaluation (BSE) by a speech pathologist. The project was approved by the Research Ethics Committee of the institution (Comitê de Ética para Análise de Projetos de Pesquisa do HCFMUSP Protocol number 0673/11). This study was approved as a retrospective review of documents without a requirement for patient consent.

\section{Patient population}

Patients were eligible if they met all of the following criteria: (1) admission to any ICU during the two-year period from June 2010 to June 2012, (2) submitted to prolonged intubation ( $>48$ hours), (3) BSE by a speech pathologist 24 to 48 hours after extubation, (4) older than 18 years of age, (5) clinical and respiratory stability and (6) more than 14 points on the Glasgow Coma Scale. Moreover, subjects were limited to those requiring assistance and presenting swallowing level $\leq 4$ according to the American Speech-Language-Hearing Association National Outcome Measurement System (ASHA NOMS) $[18,26,34]$. Patients were excluded if they (1) were making use of a tracheostomy tube, (2) presented neurologic diseases, (3) presented esophageal dysphagia and (4) had been submitted to surgical procedures involving the head and neck.

Our hospital has as a standard procedure to refer all patients submitted to prolonged intubation to a BSE. However, only patients who are clinically stable undergo a complete BSE. Based on the existing literature [18], we included in our study patients who had initial poor swallowing levels. Although these patients were clinically stable, they still depended on alternative feeding methods or had moderate diet restriction. In our practice we have observed that patients who present good initial swallowing levels (ASHA NOMS swallowing levels 5 to 7 ) have functional swallowing and need little intervention and minimal cueing.

\section{Measurements - clinical assessment of swallowing}

The BSE included the application of the Dysphagia Risk Evaluation Protocol (DREP) [35], followed by the classification of the swallowing functional level according to the ASHA NOMS [26,34].

The DREP [35] is a Brazilian bedside assessment protocol designed for the early detection of dysphagia risk. It includes the controlled offer of water and puree/ solid volumes. The DREP determines whether the patient should receive larger volumes and different textures of food and liquids, and the amount of monitoring necessary for safe feeding. The protocol is divided into two sections - the water swallow test and the puree/solid swallow test - and results are marked as either pass or fail for each one of the observed items. As determined by the authors of the protocol, patients were assessed during the swallow of $5 \mathrm{ml}$ of water offered on a syringe, 3,5 and $10 \mathrm{ml}$ of fruit puree offered on a spoon and half a piece of bread (the tests were repeated, if necessary, up to three times to confirm results). The assessment procedures consisted of 11 items for the water swallow test 
and 12 items for the puree/solid swallow test as presented in Table 1: patients were in the upright position, so that the position would not interfere in the results of the research.

The ASHA NOMS swallowing level scale is a multidimensional tool designed to measure both the supervision level required and diet level by assigning a single number between 1 to 7 (Table 2). For this study, the patients' specific diet level and level of supervision required were used to assign the ASHA NOMS swallowing scale. Initial diet and supervision levels were documented at the first clinical evaluation and at dysphagia resolution/ hospital discharge. The speech-language pathologist assigning the ASHA NOMS swallowing level had successfully passed specific training tests.

All the patients received individual swallowing treatment until dysphagia resolution or hospital discharge. Patients in this study were assisted by various staff SLPs with experience in the area of dysphagia and trained to apply the same treatment program. The amount of treatment was recorded in revenue value units (RVUs) [18]. According to the literature, each RVU represents $15 \mathrm{mi}$ nutes of actual therapy time.

\section{Prognostic indicators}

All information regarding the swallowing treatment was registered in each patient's file. Specific outcomes related to OTI were also recorded. The prognostic indicators selected for this study are aspects encompassed in the speech-language pathology scope of practice and are not formally reported by other members of the rehabilitation team [14,16-18,31]. The prognostic indicators included: dysphagia severity rate 1 (DSR1); dysphagia severity rate 2 (DSR2); time to initiate oral feeding (TOF); amount of individual treatment (RVU); number of orotracheal intubations (NOI); intubation time (IT); length of hospital stay (LS). Definitions of the prognostic indicators are presented in Table 3.

\section{Data analysis}

Analysis was performed using SPSS for Windows, version 13.0 (SPSS Inc., Chicago, IL, USA). For the present study, patients who had their swallowing classified as levels 6 or 7, according to the ASHA NOMS swallowing level scale, at dysphagia resolution/hospital discharge (DSR2) were considered as presenting good treatment outcomes. The proposed prognostic indicators were analyzed considering this goal. The purpose of this analysis was to identify which prognostic indicators were the most significant predictors of good treatment outcomes in the investigated population.

In order to show the overall results, variables were descriptively presented in contingency tables comprising absolute (n) and relative (\%) frequencies. The logistic regression model was used to examine the relationships between independent variables. As previously described, the dependent variable was considered good treatment outcome (that is ASHA NOMS levels 6 and 7). The independent variables were: gender, age, DSR1, TOF, RVU, NOI, IT and LS. All variables were analyzed using the univariate model to determine significance $(P \leq 0.10)$. All significant variables and the interactions between them were used to obtain a selection for the multivariate model $(P \leq 0.05)$, according to the simultaneous entry procedure. The variables that remained in the model were independent prognostic variables. Spearman rank correlation coefficients examined any linear association among all prognostic indicators.

\section{Results}

Of the 1,080 ICU patients who were referred to a BSE, 456 had been submitted to OTI, 85\% (388) had records of prolonged OTI. Of the remaining patients, 148 met the inclusion criteria (91 males, mean age $53.51 \pm 16.18$; 57 females, mean age $52.88 \pm 19.32$ ). Table 4 shows the overall descriptive data.

Table 5 shows the distribution of the ASHA NOMS results on the initial swallowing assessment (DSR1) and at dysphagia resolution/hospital discharge (DSR2). As observed, most of the participants were classified as level 4 by the ASHA NOMS swallowing level scale on the initial swallowing assessment (that is individuals had moderate diet restriction and/or still required the use of a feeding tube). When looking at the distribution of participants among the different ASHA NOMS levels at the initial assessment and at dysphagia resolution/hospital discharge (DSR1 $\times$ DSR2), we can observe that 103 patients improved their swallowing to ASHA NOMS levels 5 to 7.

Table 6 shows the mean RVU obtained among the different levels on the ASHA NOMS scale at the initial assessment. The results indicate that the less severe the swallowing impairment, the lower the number of RVU.

Univariate analyses performed to identify independent variables for good treatment outcomes in patients submitted to prolonged OTI are described in Table 7. Statistically significant prognostic indicators included ASHA NOMS at initial swallowing assessment (DSR1), time to initiate oral feeding (TOF) and amount of individual treatment (RVU). Multivariate logistical regression analysis (Table 8) was performed to determine whether the association between DSR1, TOF and RVU remained after the other indicators of good prognosis had been removed. In this analysis only DSR1 remained independently associated with good treatment outcomes.

The Spearman's rank correlation test was performed to identify possible correlations among the prognostic indicators used in our study (Table 9). This analysis 
Table 1 Definition of behavioral variables and oromotor test on the Dysphagia Risk Evaluation Protocol (DREP)

\begin{tabular}{|c|c|c|}
\hline & Variable & Clinician's judgment \\
\hline \multirow[t]{22}{*}{ Water swallow test $(5 \mathrm{ml})$} & \multirow[t]{2}{*}{ Extra oral loss } & $\begin{array}{l}\text { Water does not escape from the lips, manages bolus } \\
\text { adequately - pass }\end{array}$ \\
\hline & & $\begin{array}{l}\text { Difficulty in managing bolus, presents drooling/spillage } \\
\text { from the mouth - fail }\end{array}$ \\
\hline & \multirow[t]{2}{*}{ Oral transit time } & Swallows the bolus within 4 seconds - pass \\
\hline & & $\begin{array}{l}\text { Takes longer than } 4 \text { seconds to swallow bolus or does not } \\
\text { swallow - fail }\end{array}$ \\
\hline & \multirow[t]{2}{*}{ Nasal reflux } & Water does not escape from the nasal cavities - pass \\
\hline & & Water comes out from the nasal cavities - fail \\
\hline & \multirow[t]{2}{*}{ Multiple swallows per bolus } & Presents one swallow per bolus - pass \\
\hline & & $\begin{array}{l}\text { Presents more than one swallow per bolus, presents } \\
\text { drooling/spillage from the mouth, needs cues to complete } \\
\text { the task - fail }\end{array}$ \\
\hline & \multirow{2}{*}{$\begin{array}{l}\text { Laryngeal elevation (monitored by positioning the index } \\
\text { and middle fingers over the hyoid bone and the thyroid } \\
\text { cartilage) }\end{array}$} & $\begin{array}{l}\text { Reaches an average elevation of two fingers of the } \\
\text { examiner - pass }\end{array}$ \\
\hline & & $\begin{array}{l}\text { Does not present laryngeal elevation or presents average } \\
\text { elevation of less than two fingers of the examiner - fail }\end{array}$ \\
\hline & \multirow[t]{2}{*}{$\begin{array}{l}\text { Cervical auscultation (a stethoscope is placed at the lateral } \\
\text { aspects above the cricoids cartilage in front of the } \\
\text { sternocleidomastoid muscle and large vessels) }\end{array}$} & $\begin{array}{l}\text { Presents the three characteristic sounds indicating that the } \\
\text { bolus has gone through the pharynx - two clicks followed } \\
\text { by an expiratory sound - pass }\end{array}$ \\
\hline & & $\begin{array}{l}\text { Does not present any sound or sounds other than those } \\
\text { described above - fail }\end{array}$ \\
\hline & \multirow{2}{*}{$\begin{array}{c}\text { Oxygen saturation (baseline oxygen saturation registered } \\
\text { prior to the swallowing test using a monitor or pulse } \\
\text { oximetry) }\end{array}$} & $\begin{array}{l}\text { Does not present changes in oxygen saturation in more } \\
\text { than } 4 \text { units - pass }\end{array}$ \\
\hline & & $\begin{array}{l}\text { Presents changes in oxygen saturation in more than } \\
4 \text { units - fail }\end{array}$ \\
\hline & \multirow[t]{2}{*}{ Voice quality } & $\begin{array}{l}\text { Does not present any alterations within the first minute } \\
\text { after swallowing - pass }\end{array}$ \\
\hline & & $\begin{array}{l}\text { Voice becomes gurgly ('wet') within the first minute after } \\
\text { swallowing - fail }\end{array}$ \\
\hline & \multirow[t]{2}{*}{ Cough } & $\begin{array}{l}\text { Does not cough within the first minute after } \\
\text { swallowing - pass }\end{array}$ \\
\hline & & $\begin{array}{l}\text { Presence of cough (voluntary or not) followed or not } \\
\text { by throat clearing within the first minute after } \\
\text { swallowing - fail }\end{array}$ \\
\hline & \multirow[t]{2}{*}{ Choking } & Does not choke after swallowing - pass \\
\hline & & Chokes during and/or after swallowing - fail \\
\hline & \multirow[t]{2}{*}{ Other signs (cardiac and respiratory frequencies) } & $\begin{array}{l}\text { Does not present significant changes in cardiac frequency } \\
\text { (60-100 beats per minute) and in respiratory frequency } \\
\text { (12-20 breaths per minute) - pass }\end{array}$ \\
\hline & & $\begin{array}{l}\text { Presents signs of cyanoses, bronchospasm and significant } \\
\text { alterations of the vital signs - fail }\end{array}$ \\
\hline \multirow{8}{*}{$\begin{array}{l}\text { Puree/solid swallow test } \\
(3,5,10 \mathrm{ml} \text {; half a piece } \\
\text { of bread) }\end{array}$} & \multirow[t]{2}{*}{ Extra oral loss } & $\begin{array}{l}\text { Bolus does not escape from the lips, manages bolus } \\
\text { adequately - pass }\end{array}$ \\
\hline & & $\begin{array}{l}\text { Difficulty in managing the bolus, presents spillage from the } \\
\text { mouth - fail }\end{array}$ \\
\hline & \multirow[t]{2}{*}{ Oral transit time } & Swallows the bolus within 20 seconds - pass \\
\hline & & $\begin{array}{l}\text { Takes longer than } 20 \text { seconds to swallow the bolus or } \\
\text { does not swallow - fail }\end{array}$ \\
\hline & \multirow[t]{2}{*}{ Nasal reflux } & The bolus does not escape from the nasal cavities - pass \\
\hline & & The bolus comes out from the nasal cavities - fail \\
\hline & \multirow[t]{2}{*}{ Oral residue } & $\begin{array}{l}\text { Presents absence or up to } 25 \% \text { of bolus residue in the oral } \\
\text { cavity - pass }\end{array}$ \\
\hline & & $\begin{array}{l}\text { Presents more than } 25 \% \text { of bolus residue in the oral } \\
\text { cavity - fail }\end{array}$ \\
\hline
\end{tabular}


Table 1 Definition of behavioral variables and oromotor test on the Dysphagia Risk Evaluation Protocol (DREP) (Continued)

\begin{tabular}{|c|c|}
\hline \multirow[t]{2}{*}{ Multiple swallows per bolus } & Presents one to three swallows per bolus - pass \\
\hline & $\begin{array}{l}\text { Presents more than three swallows per bolus, presents } \\
\text { drooling/spillage from the mouth, needs cues to complete } \\
\text { task - fail }\end{array}$ \\
\hline \multirow{2}{*}{$\begin{array}{l}\text { Laryngeal elevation (monitored with the positioning of the } \\
\text { index and middle fingers over the hyoid bone and the } \\
\text { thyroid cartilage) }\end{array}$} & $\begin{array}{l}\text { Reaches an average elevation of two fingers of the } \\
\text { examiner - pass }\end{array}$ \\
\hline & $\begin{array}{l}\text { Does not present laryngeal elevation or presents average } \\
\text { elevation of less than two fingers of the examiner - fail }\end{array}$ \\
\hline \multirow[t]{2}{*}{$\begin{array}{l}\text { Cervical auscultation (a stethoscope is placed at the lateral } \\
\text { aspects above the cricoids cartilage in front of the } \\
\text { sternocleidomastoid muscle and large vessels) }\end{array}$} & $\begin{array}{l}\text { Presents the three characteristic sounds indicating that the } \\
\text { bolus has gone through the pharynx - two clicks followed } \\
\text { by an expiratory sound - pass }\end{array}$ \\
\hline & $\begin{array}{l}\text { Does not present any sound or sounds other than those } \\
\text { described above - fail }\end{array}$ \\
\hline \multirow{2}{*}{$\begin{array}{c}\text { Oxygen saturation (baseline oxygen saturation registered } \\
\text { prior to the swallowing test using a monitor or pulse } \\
\text { oximetry) }\end{array}$} & $\begin{array}{l}\text { Does not present changes in oxygen saturation in more } \\
\text { than } 4 \text { units - pass }\end{array}$ \\
\hline & $\begin{array}{l}\text { Presents changes in oxygen saturation in more than } 4 \\
\text { units - fail }\end{array}$ \\
\hline \multirow[t]{2}{*}{ Voice quality } & $\begin{array}{l}\text { Does not present any alterations within the first minute } \\
\text { after swallowing - pass }\end{array}$ \\
\hline & $\begin{array}{l}\text { Voice becomes gurgly ('wet') within the first minute after } \\
\text { swallowing - fail }\end{array}$ \\
\hline \multirow[t]{2}{*}{ Cough } & $\begin{array}{l}\text { Does not cough within the first minute after swallowing - } \\
\text { pass }\end{array}$ \\
\hline & $\begin{array}{l}\text { Presence of cough (voluntary or not) followed or not by } \\
\text { throat clearing within the first minute after swallowing - } \\
\text { fail }\end{array}$ \\
\hline \multirow[t]{2}{*}{ Choking } & Does not choke after swallowing - pass \\
\hline & Chokes during and/or after swallowing - fail \\
\hline \multirow[t]{2}{*}{ Other signs (cardiac and respiratory frequencies) } & $\begin{array}{l}\text { Does not present significant changes in cardiac frequency } \\
(60-100 \text { beats per minute) and in respiratory frequency } \\
(12-20 \text { breaths per minute) - pass }\end{array}$ \\
\hline & $\begin{array}{l}\text { Presents signs of cyanoses, bronchospasm and significant } \\
\text { alterations of the vital signs - fail }\end{array}$ \\
\hline
\end{tabular}

Table 2 American Speech-Language-Hearing Association National Outcome Measurement System (ASHA NOMS) swallowing level scale

\begin{tabular}{cl}
\hline Level 1 & Individual is not able to swallow safely by mouth. All nutrition and hydration is received through non-oral means (for example nasogastric tube). \\
\hline Level 3 & $\begin{array}{l}\text { Individual is not able to swallow safely by mouth for nutrition and hydration but may take some consistency with consistent maximal } \\
\text { cues in therapy only. Alternative method of feeding is required. } \\
\text { with consistent use of moderate cues to use compensatory strategies and/or requires maximum diet restriction. }\end{array}$ \\
\hline Level 4 & $\begin{array}{l}\text { Swallowing is safe but usually requires moderate cues to use compensatory strategies, and/or individual has moderate diet restriction } \\
\text { and/or still requires tube feeding and/or oral supplements. }\end{array}$ \\
\hline Level 5 & $\begin{array}{l}\text { Swallow is safe with minimal diet restriction and/or occasionally requires minimal cueing to use compensatory strategies. May occasionally } \\
\text { self cue. All nutrition and hydration needs are met by mouth at mealtime. }\end{array}$ \\
\hline Level 6 & $\begin{array}{l}\text { Swallowing is safe, and individual eats and drinks independently and may rarely require minimal cueing. Usually self cues when difficulty } \\
\text { occurs. May need to avoid specific food items (for example popcorn and nuts), or requires additional time (due to dysphagia). }\end{array}$ \\
\hline Level 7 & $\begin{array}{l}\text { Individual's ability to eat independently is not limited by swallow function. Swallowing would be safe and efficient for all consistencies. } \\
\text { Compensatory strategies are effectively used when needed. }\end{array}$ \\
\hline
\end{tabular}


Table 3 Definition of prognostic indicators

\begin{tabular}{cll}
\hline & Indicators & Definition \\
\hline \multirow{2}{*}{ General } & Dysphagia severity rate 1 (DSR1) & ASHA NOMS swallowing level at initial swallowing assessment \\
\cline { 2 - 3 } & Dysphagia severity rate 2 (DSR2) & ASHA NOMS swallowing level at dysphagia resolution/hospital discharge \\
\cline { 2 - 3 } & Time to initiate oral feeding (TOF) & Time to start oral feeding after DSR1 (in days) \\
\cline { 2 - 3 } $\begin{array}{c}\text { Specific to the group of } \begin{array}{c}\text { Amount of individual treatment (revenue } \\
\text { patients }\end{array} \\
\text { value unit (RVU)) }\end{array}$ & $\begin{array}{l}\text { Amount of individual swallowing treatment until dysphagia resolution/ } \\
\text { hospital discharge (in RVUs) }\end{array}$ \\
\cline { 2 - 3 } & $\begin{array}{ll}\text { Number of orotracheal intubations (NOI) } \\
\text { Intubation time (IT) }\end{array}$ & Total number of orotracheal intubations \\
\cline { 2 - 3 } & Length of hospital stay (LS) & Total duration of orotracheal intubation (in hours) \\
\hline
\end{tabular}

indicated a moderate negative correlation between DSR1 and TOF, and a moderate positive correlation between DSR1 and RVU. A weak negative correlation was observed between DSR1 and RVU, and weak positive correlations were observed between NOI and IT, and between RVU and LS.

\section{Discussion}

Recently, increased regulation has required rehabilitation programs to report their results and outline the goals of the rehabilitation process effectively and efficiently. It is essential to introduce prognostic/quality indicators in order to clearly understand and manage the quality of health care. Using prognostic/quality indicators in hospital units improves the analysis of performance over time as new procedures and technology are introduced [19]. This study represents the largest group of Brazilian patients submitted to prolonged OTI who have been assessed for possible prognostic indicators related to the swallowing functional outcome at hospital discharge.

In a large group of patients submitted to prolonged OTI, we have demonstrated that, among patients who were assessed by a BSE, the ASHA NOMS level at the initial swallowing assessment (DSR1), the time to initiate oral feeding (TOF) and the amount of individual treatment (RVU) were related to a higher probability of reaching good treatment outcomes for dysphagia resolution. Among these indicators, the DSR1 is the strongest predictor. Also, the

Table 4 Descriptive data

\begin{tabular}{ccccccccc}
\hline Variable & Mean & Median & SD & Min & Max & \multicolumn{3}{c}{$\mathbf{Q}$} \\
\cline { 6 - 10 } & & & & & & $\mathbf{2 5}$ & $\mathbf{5 0}$ & $\mathbf{7 5}$ \\
\hline AGE & 53.26 & 55 & 17.40 & 18 & 90 & 43 & 55 & 65 \\
\hline LS & 43.07 & 34 & 30.96 & 9 & 197 & 21 & 34 & 58 \\
\hline NOI & 1.08 & 1 & 0.27 & 1 & 2 & 1 & 1 & 1 \\
\hline IT & 187.70 & 144 & 123.25 & 0 & 720 & 4 & 6 & 10 \\
\hline TOF & 4.58 & 0 & 10.51 & 0 & 57 & 0 & 0 & 3 \\
\hline RVU & 6.59 & 4 & 5.88 & 1.33 & 41.33 & 2.67 & 4 & 8 \\
\hline
\end{tabular}

SD, Standard deviation; Min, Minimum; Max, Maximum; Q, Quartile; LS, Length of hospital stay; NOI, Number of orotracheal intubations; IT, Intubation time; TOF, Time to initiate oral feeding; RVU, Amount of individual treatment (revenue value unit).
DSR1 correlated significantly with the TOF (that is the higher the ASHA NOMS level at the initial swallowing assessment the less time is needed to initiate oral feeding) and with the RVU (that is the higher the ASHA NOMS level at the initial swallowing assessment the less intervention is needed by a therapist). This finding validates the importance of the initial assessment determining the outcome of a patient with dysphagia following prolonged OTI [18].

In accordance to our results, previous researchers also found that neither age nor the duration of intubation appears to be a significant factor affecting oral intake $[1,18,25,36]$. The literature indicates the age variable as being implicated in the presence and resolution of the swallowing impairment $[8,16,21]$. However, our study suggests that the age variable did not seem to significantly interfere in the resolution of dysphagia. According to the criteria adopted in our hospital (that is public, high complexity, high rate of bed turnover), once patients reach adequate stable clinical conditions, they are discharged. In many cases, functional swallowing has not yet been reached. According to the Brazilian Health System, patients will receive speech-language pathology follow-up in specialized health care centers. For this reason 59 patients (approximately $40 \%$ of the individuals) were discharged from the hospital even though they did not reach a good dysphagia resolution. We believe that if these patients were followed until dysphagia resolution, our results would probably indicate significant differences regarding the variable age.

The association between intubation duration and severity of dysphagia is supported by the Barker et al. review [15] and other studies [6,15]. However, this association has not been reported in other analyses $[1,8,12,37,38]$. The study presented by Stauffer et al. [38] indicated no correlation between the duration of endotracheal intubation in intubated patients and the severity of laryngeal lesions. Many factors could account for this discrepancy, such as differences in sample size, event rate and intubation duration. Although this association is plausible based on the likely increased degree of oral, pharyngeal and laryngeal damage in patients intubated for long periods, it also 
Table 5 Distribution of the American Speech-Language-Hearing Association National Outcome Measurement System (ASHA NOMS) levels at initial swallowing assessment (DSR1) and at discharge (DSR2)

\begin{tabular}{|c|c|c|c|c|}
\hline \multirow[b]{2}{*}{ ASHA NOMS levels } & \multicolumn{2}{|c|}{$\begin{array}{c}\text { ASHA NOMS levels at initial swallowing } \\
\text { assessment }\end{array}$} & \multicolumn{2}{|c|}{$\begin{array}{l}\text { ASHA NOMS levels at } \\
\text { discharge }\end{array}$} \\
\hline & $\mathbf{N}$ & $\%$ & $\mathbf{N}$ & $\%$ \\
\hline 1. Not able to swallow by mouth & 10 & 6.75 & 7 & 4.73 \\
\hline 2. Takes some consistency with maximal cues & 48 & 32.43 & 11 & 7.43 \\
\hline 3. Takes less than $50 \%$ of nutrition by mouth with moderate cues & 27 & 18.24 & 12 & 8.11 \\
\hline 4. Swallowing is safe with moderate cues & 63 & 42.56 & 15 & 10.14 \\
\hline 5. Swallowing is safe with minimal cues & 0 & 0 & 14 & 9.65 \\
\hline 6. Swallowing is safe and rarely requires minimal cues & 0 & 0 & 36 & 24.31 \\
\hline 7. Swallowing is efficient, individual is independent & 0 & 0 & 53 & 35.81 \\
\hline
\end{tabular}

$D S R 1$, Dysphagia severity rate $1 ; D S R 2$, Dysphagia severity rate $2 ; N$, Number of patients; \% percentage.

remains possible that short intubation duration is sufficient to cause dysphagia [39]. The association between intubation duration and dysphagia most certainly needs to be further explored.

We would like to highlight that the result related to the time to initiate oral feeding. Based on our results, we believe that the earlier oral feeding is introduced the higher the probability of reaching good dysphagia outcomes. We also found positive results regarding the recovery of swallowing impairment until dysphagia resolution/ hospital discharge. We observed that most patients presented a favorable progression of oral intake. This general pattern of improvement in the swallowing ability during the length of hospital stay is similar to the pattern of positive outcomes that have been previously reported in the specialized literature $[17,18,25]$.

Our study also showed that poorer swallowing status at the initial swallowing assessment is a good indicator of longer swallowing management. Our findings agree with those of other studies in that preadmission functional status was also a highly relevant prognostic factor of amount of treatment (that is RVU) $[14,18,40]$. Previous studies suggest that a lack of accuracy in initial evaluation could impact both the dietary level assigned

Table 6 Mean revenue value units according to the dysphagia severity rate at the initial assessment

\begin{tabular}{lcc}
\hline DSR1 - ASHA NOMS level & N & $\begin{array}{c}\text { RVU } \\
\text { (mean) }\end{array}$ \\
\hline 1. Not able to swallow by mouth & 10 & 13.73 \\
\hline 2. Takes some consistency with maximal cues & 48 & 7.50 \\
\hline $\begin{array}{l}\text { 3. Takes less than 50\% of nutrition by mouth with } \\
\text { moderate cues }\end{array}$ & 27 & 6.52 \\
\hline $\begin{array}{l}\text { 4. Swallowing is safe with moderate cues } \\
\text { 5. Swallowing is safe with minimal cues }\end{array}$ & 63 & 4.80 \\
\hline 6. Swallowing is safe and rarely requires minimal cues & - & - \\
\hline 7. Swallowing is efficient, individual is independent. & - & - \\
\hline DSR1, Dysphata severity rat 1; $N$ Number of patients; RVU, Revenue
\end{tabular}

$D S R 1$, Dysphagia severity rate $1 ; N$, Number of patients; $R V U$, Revenue value unit. to patients and therefore the amount and type of treatment received [18]. The use of functional rating scales to evaluate patients with swallowing disorders has emerged over the past years [27,41-43]. Several screening methods for dysphagia have been validated [44-46]. In this study, a validated reliable clinical bedside protocol was used.

Finally, our study had several limitations. First, the results of this study have been derived from a hospital-referred cohort of patients after prolonged OTI and therefore may reflect some hospital-referral bias. Second, the conclusions drawn can only be applied to patients exhibiting some degree of dysphagia as previously discussed. Third, the clinical assessment of impaired swallowing has evident limitations and a videofluoroscopy (VFS) examination would be required for all patients. However, clinical examination, cervical auscultation and oximetry changes (that is BSE) increased the diagnostic sensitivity, and thus, the probability of identifying patients with silent aspiration [45]. Also we have to consider that although VFS is the gold standard to study oral and pharyngeal mechanisms of dysphagia

Table 7 Logistic regression (univariate analysis) of the independent variables for good treatment outcomes (DSR2 levels 6/7)

\begin{tabular}{lccc}
\hline & OR & $\boldsymbol{P}$ value & Cl (95\%) \\
\hline DSR1 & 2.294 & $0.001^{*}$ & $1.590-3.310$ \\
\hline Gender & 1.569 & 0.200 & $0.788-3.124$ \\
\hline Age & 0.989 & 0.253 & $0.970-1.008$ \\
\hline TOF & 0.960 & $0.025^{*}$ & $0.926-0.995$ \\
\hline RVU & 0.949 & $0.085^{*}$ & $0.894-1.007$ \\
\hline NOI & 0.922 & 0.894 & $0.278-3.055$ \\
\hline IT & 1.011 & 0.742 & $0.947-1.079$ \\
\hline LS & 0.998 & 0.665 & $0.987-1.008$ \\
\hline
\end{tabular}

*Significant result. DSR2, Dysphagia severity rate 2; OR, Odds ratio; $\mathrm{Cl}$, Confidence interval; $D S R 1$, Dysphagia severity rate $1 ; T O F$, Time to initiate oral feeding; RVU, Amount of individual treatment (revenue value unit); NOI, Number of orotracheal intubations; IT, Intubation time; $L S$, Length of hospital stay. 
Table 8 Logistic regression (multivariate analysis) of the independent variables for good treatment outcomes (DSR2 levels 6/7)

\begin{tabular}{lccc}
\hline & OR & $\boldsymbol{P}$ value & Cl (95\%) \\
\hline DSR1 & 1.547 & 0.050 & $0.999-2.396$ \\
TOF & 0.986 & 0.560 & $0.942-1.033$ \\
RVU & 0.964 & 0.394 & $0.885-1.049$ \\
\hline DSR2
\end{tabular}

$D S R 2$, Dysphagia severity rate $2 ; O R$, Odds ratio; $C l$, Confidence interval; $D S R 1$, Dysphagia severity rate $1 ; T O F$, Time to initiate oral feeding; RVU, Amount of individual treatment (revenue value unit).

and aspiration [39,47,48], it is unfeasible to perform a VFS on every patient with dysphagia (that is age, medical condition, costs and so on). A simple BSE can be used to identify patients at risk for dysphagia after prolonged OTI [6]. Third, inherent in the design of our retrospective, observational cohort study is an inability to draw conclusions about the severity of the diseases of the patients included in the study. Since patients were recruited from different ICUs of our hospital, we were unable to reach a consensus of which information could be used to characterize patients' clinical status severity (that is each ICU uses a different protocol to determine disease severity). Similarly, some very important variables were inconsistently charted or not charted at all, thus were not available for our analysis. For example, we were unable to obtain (1) a reliable marker of sedation at the time of swallow assessment; (2) height data to calculate body mass index; (3) data on the presence of preexisting swallowing dysfunction; (4) information about endotracheal tube size. Future studies in our institution will most certainly include these variables.

Dysphagia is a major side effect of prolonged OTI. Prognostic data can be beneficial to health professionals, rehabilitative facilities providing care, insurance companies, and patients and their families. When looking at developing countries, the prolonged intensive medical and nursing care required by many patients places extra demands on a stretched health care budget [49]. Knowing the statistically significant factors that contribute to patient outcome as determined by this study reiterates the urgency for accuracy and consistency during the initial assessment within a health facility.

\section{Conclusions}

The main contribution of the current research is related to the swallowing functional level at admission as a significant prognostic indicator of good swallowing outcome (that is ASHA NOMs level 6/7). The level of swallowing impairment, the time to initiate oral feeding and the amount of individual treatment can be used as clinical indicators to predict swallowing rehabilitation outcomes.

Given the current trend of having an evidence-based practice, studies of prognostic indicators in different populations with dysphagia can contribute to the design of more effective procedures when evaluating, treating, and monitoring individuals with this type of disorder. We believe that the measurement of prognostic indicators for swallowing rehabilitation outcomes should be routinely included in interdisciplinary hospital practice.

\section{Key messages}

- The development of postextubation swallowing dysfunction is well documented in the literature with high prevalence in most studies, ranging from 44 to $87 \%$.

- The results of this study suggest the swallowing functional level at admission as a significant prognostic indicator of good swallowing outcome.

- This study represents the largest group of Brazilian patients submitted to prolonged OTI who have been assessed for possible prognostic indicators related to the swallowing functional outcome at hospital discharge.

- Postextubation dysphagia persists at the time of discharge in a large portion of patients (59 (40\%) of 148 patients in our study).

Table 9 Correlation results for the prognostic indicators

\begin{tabular}{|c|c|c|c|c|c|c|c|c|c|c|c|c|c|c|}
\hline & \multicolumn{2}{|c|}{ Gender } & \multicolumn{2}{|c|}{ Age } & \multicolumn{2}{|c|}{ TOF } & \multicolumn{2}{|c|}{ RVU } & \multicolumn{2}{|c|}{$\mathrm{NOI}$} & \multicolumn{2}{|c|}{ IT } & \multicolumn{2}{|c|}{ LS } \\
\hline & $r$ & $P$ & $r$ & $P$ & $r$ & $P$ & $r$ & $P$ & $r$ & $P$ & $r$ & $P$ & $r$ & $P$ \\
\hline DSR1 & -0.403 & 0.68 & -0.142 & 0.08 & -0.590 & 0.00 & -0.322 & 0.00 & 0.014 & 0.86 & -0.051 & 0.53 & -0.018 & 0.82 \\
\hline Gender & - & - & -0.067 & 0.94 & -0.421 & 0.67 & -0.258 & 0.79 & -0.383 & 0.70 & -0.950 & 0.34 & -0.337 & 0.73 \\
\hline Age & - & - & - & - & 0.172 & 0.48 & 0.182 & 0.02 & -0.017 & 0.83 & -0.159 & 0.54 & 0.039 & 0.63 \\
\hline TOF & - & - & - & - & - & - & 0.584 & 0.00 & -0.031 & 0.72 & 0.064 & 0.46 & 0.159 & 0.06 \\
\hline RVU & - & - & - & - & - & - & - & - & -0.139 & 0.09 & 0.073 & 0.38 & 0.300 & 0.00 \\
\hline NOI & - & - & - & - & - & - & - & - & - & - & 0.340 & 0.00 & 0.237 & 0.00 \\
\hline IT & - & - & - & - & - & - & - & - & - & - & - & - & 0.165 & 0.04 \\
\hline
\end{tabular}

TOF, Time to initiate oral feeding; RVU, Amount of individual treatment (revenue value unit); NOI, Number of orotracheal intubations; IT, Intubation time; $L S$, Length of hospital stay; $r$, Spearman's correlation coefficient; $P$, significance value; DSR1, Dysphagia severity rate 1. 
- When looking at developing countries, the prolonged intensive medical and nursing care required by many patients places extra demands on a stretched health care budget. Knowing the statistically significant factors that contribute to patient outcome as determined by this study reiterates the urgency for accuracy and consistency during the initial assessment within a health facility.

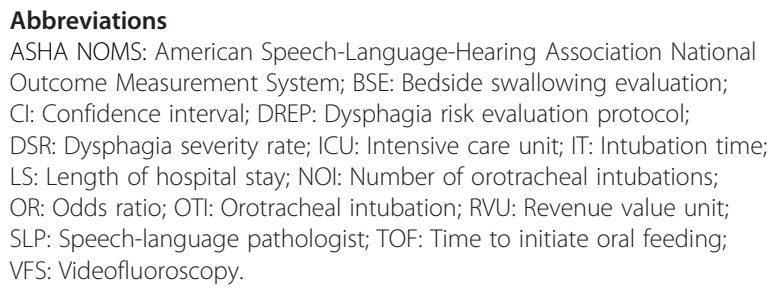

\section{Competing interests}

The authors declare that they have no competing interests.

\section{Authors' contributions}

DPM contributed to data collection and analysis, to the interpretation of the results, to the manuscript writing and provided substantial scientific contribution. FCS contributed to the interpretation of the results and manuscript preparation. LDM contributed to the data collection and analysis. BZ contributed to the study analysis and manuscript preparation. CRFA conceived the study, and contributed to data analysis and manuscript preparation. All authors have read and approved the manuscript.

\section{Author details}

${ }^{1}$ Hospital das Clínicas, School of Medicine, University of São Paulo, Rua Ovídeo Pires de Campos, 186, Cerqueira César, CEP 054030-010 São Paulo, SP, Brazil. ${ }^{2}$ Department of Physiotherapy, Speech-Language and Hearing Sciences, and Occupational Therapy, School of Medicine, University of São Paulo, Rua Ovídeo Pires de Campos, 186, Cerqueira César, CEP 054030-010 São Paulo, SP, Brazil. ${ }^{3}$ Medical Investigation Laboratory (LIM 34) -

Rehabilitation Sciences, School of Medicine, University of São Paulo, Rua Ovídeo Pires de Campos, 186, Cerqueira César, CEP 054030-010 São Paulo, SP, Brazil. ${ }^{4}$ Digestive Surgery Division, School of Medicine, University of São Paulo, Rua Ovídeo Pires de Campos, 186, Cerqueira César, CEP 054030-010 São Paulo, SP, Brazil.

Received: 6 March 2013 Accepted: 27 August 2013

Published: 18 October 2013

\section{References}

1. Solh EA, Okada M, Bhat A, Pietrantoni C: Swallowing disorders post orotracheal intubation in the elderly. Intensive Care Med 2003, 29:1451-1455.

2. Heffner JE: Swallowing complications after endotracheal extubation: moving from "whether" to "how". Chest 2010, 137:509-510.

3. de Larminat V, Montravers P, Dureuil B, Desmonts JM: Alteration in swallowing reflex after extubation in intensive care unit patients. Crit Care Med 1995, 23:486-490.

4. Morgan AS, Mackay LE: Causes and complications associated with swallowing disorders in traumatic brain injury. J Head Trauma Rehabil 1999, 14:454-461.

5. Martin-Harris B, Brodsky MB, Price CC, Michel Y, Walters B: Temporal coordination of pharyngeal and laryngeal dynamics with breathing during swallowing: single liquid swallows. J Appl Physiol 2003, 94:1735-1743.

6. Brown CVR, Hejl K, Mandaville AD, Chaney PE, Stevenson G, Smith C: Swallowing dysfunction after mechanical ventilation in trauma patients. J Crit Care 2011, 26:e9-e13.

7. Leder SB, Cohn SM, Moller BA: Fiberoptic endoscopic documentation of the high incidence of aspiration following extubation in critically ill trauma patients. Dysphagia 1998, 13:208-212.
8. Barquist $\mathrm{E}$, Brown M, Cohn S, Lundy D, Jackowski J: Postextubation fiberoptic endoscopic evaluation of swallowing after prolonged endotracheal intubation: a randomized, prospective trial. Crit Care Med 2001, 29:1710-1713.

9. Partik B, Pokieser P, Schima W, Schober E, Stadler A, Eisenhuber E, Denk D, Lechner G: Videofluoroscopy of swallowing in symptomatic patients who have undergone long-term intubation. AJR Am J Roentgenol 2000, 174:1409-1412.

10. Kozlow JH, Berenholz SM, Garrett E, Dorman T, Pronovost PJ: Epidemiology and impact of aspiration pneumonia in patients undergoing surgery in Maryland 1999-2000. Crit Care Med 2003, 31:1930-1937.

11. Skoretz SA, Flowers HL, Martino R: The incidence of dysphagia following endotracheal intubation: a systematic review. Chest 2010, 137:665-673.

12. Ajemian MS, Nirmul GB, Anderson MT, Zirlen DM, Kwasnik EM: Routine fiberoptic endoscopic evaluation of swallowing following prolonged intubation: implications for management. Arch Surg 2011, 136:434-437.

13. Postma G, McGuirt F, Butler SG, Rees CJ, Crandall HL, Tansavatdi K: Laryngopharyngeal abnormalities in hospitalized patients with dysphagia. Laryngoscope 2007, 117:1720-1722.

14. Rumbach AF, Ward EC, Cornwell PL, Bassett LV, Muller JM: Clinical progression and outcome of dysphagia following thermal burn injury: a prospective cohort study. J Burn Care Res 2012, 33:336-346.

15. Barker J, Martino R, Reichardt B, Hickey EJ, Ralph-Edwards A: Incidence and impact of dysphagia in patients receiving prolonged endotracheal intubation after cardiac surgery. Can J Surg 2009, 52:119-124.

16. Bordon A, Bokhari R, Sperry J, Testa D, Feinstein A, Ghaemmaghami V: Swallowing dysfunction after prolonged intubation: analysis of risk factors in trauma patients. Am J Surg 2011, 202:679-682.

17. Ward EC, Green K, Morton AL: Patterns and predictors of swallowing resolution following adult traumatic brain injury. J Head Trauma Rehabil 2007, 22:184-191.

18. McMicken BL, Muzzy CL: Prognostic indicators of functional outcomes in first time documented acute stroke patients following standard dysphagia treatment. Disabil Rehabil 2009, 31:2196-2203.

19. Moraes DP, Andrade CRF: Quality indicators for integrated care of dysphagia in hospital settings. J Soc Bras Fonoaudiol 2011, 23:89-94.

20. Schindler JS, Kelly JH: Swallowing disorders in the elderly. Laryngoscope 2002, 112:589-602.

21. Leder S, Suiter DM: An epidemiologic study on aging and dysphagia in the acute care hospitalized population: 2000-2007. Gerontology 2009, 55:714-718.

22. Halper AS, Cherney LR, Cichowski K, Zhang M: Dysphagia after head trauma: the effect of cognitive-communicative impairments on functional outcomes. J Head Trauma Rehabil 1999, 14:486-496.

23. Terré $R$, Mearin F: Oropharyngeal dysphagia after the acute phase of stroke: predictors of aspiration. Neurogastroenterol Motil 2006, 18:200-205.

24. Becker R, Nieczaj F, Egge K, Moll A, Meinhardt M, Schulz RJ: Functional dysphagia therapy and PEG treatment in a clinical geriatric setting. Dysphagia 2011, 26:108-116.

25. Mackay LE, Morgan AS, Bernstein BA: Factors affecting oral feeding with severe traumatic brain injury. Head Trauma Rehabil 1999, 14:435-447.

26. Wesling M, Brady S, Jensen M, Nickell M, Statkus D, Escobar N: Dysphagia outcomes in patients with brain tumors undergoing inpatient rehabilitation. Dysphagia 2003, 18:203-210.

27. Crary MA, Mann GD, Groher ME: Initial psychometric assessment of a functional oral intake scale for dysphagia in stroke patients. Arch Phys Med Rehabil 2005, 86:1516-1520.

28. Schindler A, Vincon E, Grosso E, Miletto AM, Di Rosa R, Schindler O: Rehabilitative management of oropharyngeal dysphagia in acute care settings: data from a large Italian teaching hospital. Dysphagia 2008, 23:230-236

29. Monteleoni C, Clark E: Using rapid-cycle quality improvement methodology to reduce feeding tubes in patients with advanced dementia: before and after study. BMJ 2004, 329:491-494.

30. Mangilli LD, Sassi FC, Medeiros GC, Andrade CRF: Rehabilitative management of swallowing and oral-motor movements in patients with tetanus of a public service in Brazil. Acta Trop 2012, 122:241-246.

31. Frank U, Mader M, Sticher H: Dysphagic patients with tracheotomies: a multidisciplinary approach to treatment and decannulation management. Dysphagia 2007, 22:20-29. 
32. Starks B, Harbert C: Aspiration prevention protocol: decreasing postoperative pneumonia in heart surgery patients. Crit Care Nurse 2011, 31:38-45.

33. Luker JA, Wall J, Bernhardt J, Edwards I, Grimmer-Somers K: Measuring the quality of dysphagia management practices following stroke: a systematic review. Int I Stroke 2010, 5:466-476.

34. American Speech-Language-Hearing Association National Outcome Measurement System (NOMS): Adult Speech-Language Pathology User's guide. Rockville (MD): National Center for Evidence-Based Practice in Communication Disorders; 2003. http://asha.org/members/research/noms/.

35. Padovani AR, Moraes DP, Mangilli L, Andrade CRF: Protocolo do risco para disfagia (PARD). In Disfagia: prática baseada em evidência. 1st ed. Edited by Andrade CRF and Limongi SCO. Sarvier, São Paulo; 2012:62-73.

36. Schroeder MF, Daniels SK, MCClain M, Corey DM, Foundas AL: Clinical and cognitive predictors of swallowing recovery in stroke. J Rehabil Res Dev 2006, 43:301-310.

37. Romero CM, Marambio A, Larrondo J, Walker L, Lira MT, Tobar E, Cornejo R, Ruiz M: Swallowing dysfunction in nonneurologic critically ill patients who require percurtaneous dilatational tracheostomy. Chest 2010, 137:1278-1282.

38. Stauffer JL, Olson DE, Petty TL: Complications and consequences of endotracheal intubation and tracheotomy. Am J Med 1981, 70:65-76.

39. Macht M, Wimbish T, Clark BJ, Benson AB, Burnham EL, Williams A, Moss M: Postextubation dysphagia is persistent and associated with poor outcomes in survivors of critical illness. Crit Care 2011, 15:R231.

40. Cabre M, Serra-Prat, Palomera E, Almirall J, Pallares R, Clavé P: Prevalence and prognostic implications of dysphagia in elderly patients with pneumonia. Age Aging 2010, 39:39-45.

41. Broadley S, Cheek A, Salonikis S, Whitham E, Chong V, Cardone D, Alexander B, Taylor J, Thompson P: Predicting prolonged dysphagia in acute stroke: the Royal Adelaide Prognostic Index for Dysphagic Stroke (RAPIDS). Dysphagia 2005, 20:303-310.

42. Broadley S, Croser D, Cottrell J, Creevy M, Teo E, Yiu D, Pathi R, Taylor J, Thompson PD: Predictors of prolonged dysphagia following acute stroke. J Clin Neurosci 2003, 10:300-305.

43. Skeat J, Perry A: Outcome measurement in dysphagia: not so hard to swallow. Dysphagia 2005, 20:113-122

44. Smith HÁ, Lee S, O'Neill PA, Connolly M: The combination of bedside swallowing assessment and oxygen saturation monitoring of swallowing in acute stroke: a safe and humane screening tool. Age Aging 2000, 29:495-499.

45. Clavé P, Arreola V, Romea M, Medina L, Palomera E, Serra-Prat M: Accuracy of the volume-viscosity swallow test for clinical screening of oropharyngeal dysphagia and aspiration. Clin Nutr 2008, 27:806-815

46. Zaidi NH, Smith HA, King SC, Park C, O'Neill PA, Connolly MJ: Oxygen desaturation on swallowing as a potential marker of aspiration in acute stroke. Age Ageing 1995, 54:S59-S65.

47. Clave P, Verdaguer A, Arreola V: Oral-pharyngeal dysphagia in elderly. Med Clin 2005, 124:742-748.

48. Almirall J, Cabre M, Clave P: Aspiration pneumonia. Med Clin 2007, 129:424-432.

49. Thwaites CL, Farra JJ: Preventing and treating tetanus. BMJ 2003, 326:117-118.

\section{Submit your next manuscript to BioMed Central and take full advantage of:}

- Convenient online submission

- Thorough peer review

- No space constraints or color figure charges

- Immediate publication on acceptance

- Inclusion in PubMed, CAS, Scopus and Google Scholar

- Research which is freely available for redistribution

Submit your manuscript at www.biomedcentral.com/submit
( Biomed Central 